\title{
OPTIMAL PERFORMANCE OF SELF EXCITED INDUCTION GENERATOR USING TEACHING LEARNING-BASED OPTIMIZATION ALGORITHM AND STATIC VAR COMPENSATOR
}

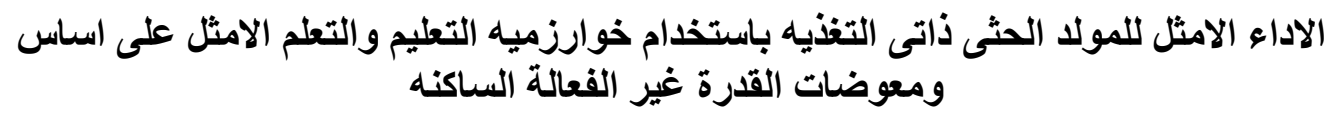

\author{
Mahmoud M. Elkholy \\ Electrical Power and Machines Department, Faculty of Engineering, Zagazig University, \\ Zagazig, Egypt \\ melkholy71@yahoo.com
}

\begin{abstract}
The paper presents an application of Teaching Learning-Based Optimization (TLBO) algorithm to improve the performance of self-excited induction generators (SEIG). Two control methods of SEIG have been studied. The first method, the TLBO algorithm is applied to generate the optimal capacitance to maintain rated voltage with constant prime mover speed. The drawback of this method is the generator frequency decreases with load and to overcome this disadvantage, the other control method is proposed. In the proposed method, the TLBO is used to obtain optimal capacitance and prime mover speed to have rated load voltage and frequency. The Static VAR Compensator (SVC) of fixed capacitor and controlled reactor is used to control the reactive power. The parameters of SVC are obtained by using TLBO algorithm. The performance of the SEIG at different loads and prime mover speeds using TLBO algorithm is realized. A whole system of three phase induction generator and SVC is established under MatLab/Simulink environment. The performance of the SEIG is demonstrated on two different ratings (i.e. $10 \mathrm{hp}$ and $2 \mathrm{hp}$ ). An experimental setup is built-up using a $2 \mathrm{hp}$ induction motor to confirm the theoretical analysis. Good agreement between results confirms and signifies the viability of the proposed TLBO-based methodology.

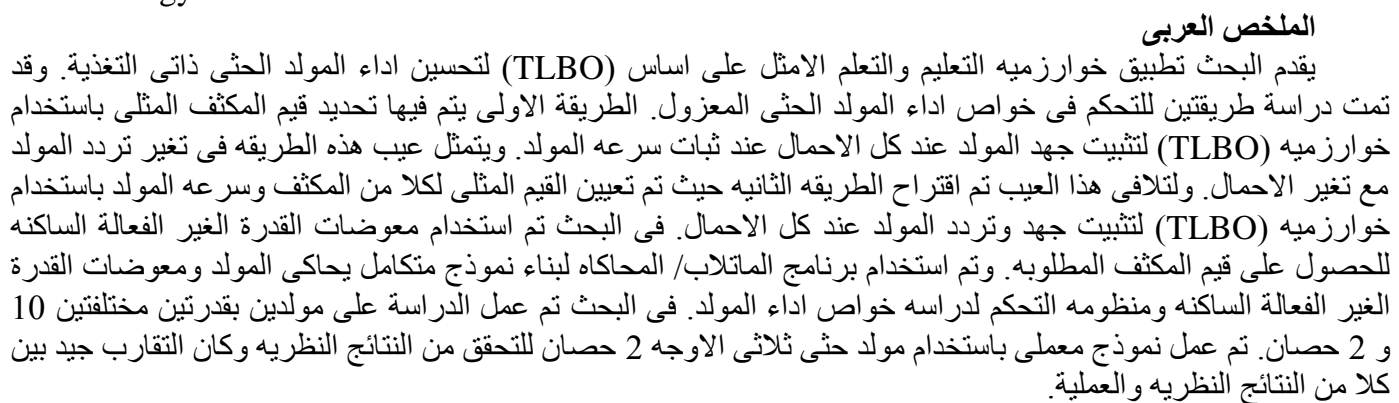

Keywords: Self-excited induction generators; constant voltage; constant frequency; static VAR compensator; teaching learning based optimization

\section{Introduction}

The self-excited induction generators (SEIG) have been received great attention during last decades. SEIGs are the most suitable power solution for remote areas because of their lower unit cost, inherent ruggedness and maintenance simplicity compared to DC and synchronous machines. These machines are available in the ranges of fractional $\mathrm{hp}$ to MW capacities [1]. In a common practice, the required reactive power for the generator and its load can be provided by the terminal static capacitor banks. The value of the capacitance required for excitation depends on the load current, power factor and the rotor speed, causing unsatisfactory voltage and frequency regulation problem [2-3].Various researches have discussed the issue of voltage regulation of SEIG and they suggested somehow effective solutions [4-10]. A very simple method uses controlled capacitors connected to the generator terminals [4-7]. Another method uses switched capacitor in order to change the capacitance with 
load variation to provide a good voltage regulation by simple and fast control method using GTO and/or IGBT switches. A static VAR compensator (SVC) is used to have a combination of switching capacitors and controllable reactors in order to provide continuous control of the reactive current [8-10].

Poor frequency regulation due to the SEIG's loading appears as another serious problem standing in the operation of SEIG. Many researchers have been attempted to solve this problem using the development of power electronics [11-15]. They suggested to convert the terminal voltage of the induction generator from $\mathrm{AC}$ to $\mathrm{DC}$ voltage using rectifiers and then from DC to AC by using PWM inverters with certain frequency. The other solution of frequency and voltage problems of SEIG is to use an Electronic Load Controller (ELC) for regulating its voltage and frequency under varying load conditions [16]. However, this solution generates harmonics on AC side of the SEIG system.

During last three decades, meta- heuristic algorithms are used to solve complicated engineering problems and to improve the performance of electrical machines [17-20]. One of the recent algorithms namely, Teaching Learning Based Optimization (TLBO) algorithm is developed [21-22]. The advantageous of TLBO algorithm is less controlling parameters viz. only population size and number of generations which save lot of efforts. As a result, TLBO can be said as an algorithm's specific parameter-less algorithm. [23-24]

This paper presents an application of TLBO algorithm to study the steady state and dynamic performance of SEIG. Two different modes of operations have been presented. The first one is the operation at constant voltage by controlling capacitor and constant prime mover speed. The second one is the operation at constant voltage and frequency by controlling both capacitor and prime mover speed. The TLBO algorithm is used to obtain optimal capacitance in the first mode of operation. The TLBO algorithm determines the optimal capacitors and prime mover speed to have constant voltage and frequency in the second mode of operation. The SVC is used to have continuous variation of excitation capacitors to have rated load voltage. The modeling of the SEIG, SVC and PI controller is developed using MatLab/Simulink. The accuracy of the proposed model and simulation is validated by building an experimental model of $2 \mathrm{hp}$ induction motor.

\section{Steady state model of SEIG}

The steady state operation of the SEIG is analyzed using the equivalent circuit shown in Fig. 1[4].Nodal admittance technique is used to solve the equivalent circuit. The generator frequency varies with the load current and the rotor speed. Moreover, the generator reactance values changes with the frequency. Therefore, the ratio between the generator frequency and the base frequency must be taken into consideration.

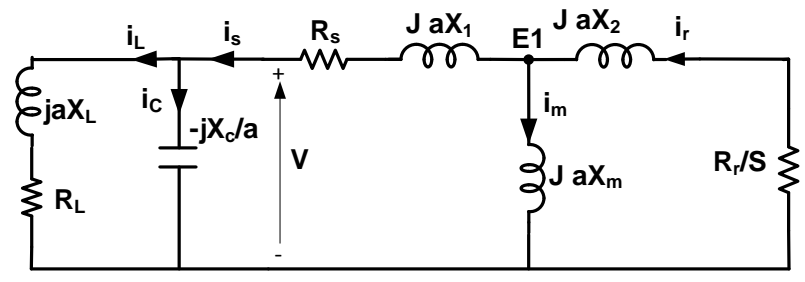

Fig. 1 Equivalent circuit of self-excited induction generator

where; $a$ is the frequency ratio $\left(a=\frac{f}{f_{b}}\right), f$ is the actual frequency, $f_{b}$ is the base frequency, $R_{s}$ is the stator winding resistance, $X_{1}$ is the stator leakage reactance $\left(X_{1}=2 \pi f_{b} L_{1}\right), X_{m}$ is the magnetizing reactance $\left(X_{m}=2 \pi f_{b} L_{m}\right), R_{r}$ is the referred rotor winding resistance, $X_{2}$ is the referred rotor leakage reactance $\left(X_{2}=2 \pi f_{b} L_{2}\right), R_{L}$ is the load resistance, $X_{L}$ is the load reactance $\left(X_{L}=2 \pi f_{b} L_{L}\right), X_{c}$ is the capacitor reactance $\left(X_{c}=1 /\left(2 \pi f_{b} C\right)\right.$ and $S$ is generator slip.

The equivalent circuit has four unknown variables ( $a$, $S, X_{m}$ and $X_{c}$ ).For an assumed values of $a$ and $C$, the other two unknown variables $\left(S\right.$ and $X_{m}$ ).can be calculated as Eqs.(1) and (2).

$$
\begin{gathered}
\begin{aligned}
K_{1}=a^{2} R_{1 L} X_{2}^{2} ; & K_{2}=R_{r}\left(R_{1 L}^{2}+X_{1 L}^{2}\right) ; K_{3} \\
= & R_{1 L} R_{r}^{2} ; R_{1 L}=\mathrm{R}_{\mathrm{s}}+R_{L C} ; X_{1 L} \\
= & \frac{R_{L} \frac{X_{C}^{2}}{a^{2}}}{R_{L}^{2}+\left(a X_{L}-\frac{X_{c}}{a}\right)^{2}}
\end{aligned} \\
X_{L C}=\frac{X_{L} \frac{X_{C}^{2}}{a^{2}}-A X_{L}^{2} X_{c}-R_{L}^{2} \frac{X_{C}}{a}}{R_{L}^{2}+\left(a X_{L}-\frac{X_{C}}{a}\right)^{2}} \\
\text { The rotor speed can be given as: } \\
n=(1-s) \frac{120 a f_{b}}{p}
\end{gathered}
$$

Where; $p$ is the number of poles.

The Excitation voltage (E) is obtained using (a), $\left(\mathrm{X}_{\mathrm{m}}\right)$ and magnetizing curve of the generator.

The stator current $\left(i_{s}\right)$, load voltage $(V)$ and load current $\left(i_{L}\right)$ are given as:

$$
\begin{gathered}
i_{s}=\frac{E_{1}}{R_{1 L}+j X_{1 L}} \\
V=E-i_{s}\left(R_{S}+j a X_{1}\right) \\
I_{L}=\frac{V}{R_{L}+j a X_{L}}
\end{gathered}
$$


The presumed values of $a$ and $C$, are acceptable if the generator voltage and speed equal reference values.

A Computer program is developed based on MATLAB package to obtain the optimum values of excitation capacitance to generate rated voltage at prime mover speed using TLBO algorithm.

\section{Dynamic model of SEIG}

The dynamic model is developed to study the dynamic performance of SEIG under step change in load and speed. The mathematical model of SEIG in stationary reference frame is described using the following equations after many simplifications [2527].

The d-q stator and referred rotor currents $\left(i_{s d}, i_{s q}, i_{r d}\right.$ and $\left.i_{r q}\right)$ are given as:

$$
\begin{gathered}
\frac{d i_{s d}}{d t}=\frac{1}{L_{\sigma}}\left[L_{r} V_{s d}-L_{r} R_{s} i_{s d}+L_{m} R_{r} i_{r d}\right. \\
\left.+\omega L_{m} L_{r} i_{r q}+\omega L_{m}{ }^{2} i_{s q}\right] \\
\begin{array}{c}
\frac{d i_{s q}}{d t}=\frac{1}{L_{\sigma}}\left[L_{r} V_{s q}-L_{r} R_{s} i_{s q}+L_{m} R_{r} i_{r q}\right. \\
\left.-\omega L_{m} L_{r} i_{r d}-\omega L_{m}{ }^{2} i_{s d}\right] \\
\frac{d i_{r d}}{d t}=\frac{1}{L_{\sigma}}\left[-L_{m} V_{s d}-L_{s} R_{r} i_{r d}+L_{m} R_{s} i_{s d}\right. \\
\left.-\omega L_{s} L_{r} i_{r q}-\omega L_{s} L_{m} i_{s q}\right] \\
\frac{d i_{r q}}{d t}=\frac{1}{L_{\sigma}}\left[-L_{m} V_{s q}-L_{s} R_{r} i_{r q}+L_{m} R_{s} i_{s q}\right. \\
+\omega L_{s} L_{r} i_{r d} \\
\left.+\omega L_{s} L_{m} i_{s d}\right]
\end{array}
\end{gathered}
$$

where; $L_{s}$ is the stator self inductance, $L_{r}$ is the referred rotor self inductance, $L_{m}$ is the magnetizing inductance, $\omega$ is the rotor speed in electrical $\mathrm{rad} / \mathrm{s}$. and $L_{\sigma}$ is defined as shown in Eq. (11).

$$
L_{\sigma}=L_{s} L_{r}-L_{m}^{2}
$$

After solving the a for mentioned differential equations, the magnetizing current $\left(i_{m}\right)$ is defined as shown in Eq. (12).

$$
i_{m}=\sqrt{\left(i_{s d}+i_{r d}\right)^{2}+\left(i_{s q}+i_{r q}\right)^{2}}
$$

The electromagnetic torque $\left(T_{e}\right)$ of the induction generator is defined in Eq. (13) and the mechanical dynamic equation of the generator is described in Eq. (14).

$$
\begin{gathered}
T_{e}=\frac{3}{2} \frac{p}{2} L_{m}\left(i_{s q} i_{r d}-i_{s d} i_{r q}\right) \\
T_{e}-T_{L}=J \frac{d \omega_{m}}{d t}+B \omega_{m}
\end{gathered}
$$

Where; $J$ is the moment of inertia in $\mathrm{Kg} \cdot \mathrm{m}^{2}, B$ is the rotor friction coefficient and $\omega_{m}$ is the rotor speed in mechanical rad/s.

The d-q load current $\left(i_{L d}\right.$ and $\left.i_{L q}\right)$ can be described in Eqs. (15) and (16); respectively.

$$
R_{L} i_{L d}+L_{L} \frac{d i_{L d}}{d t}+i_{s d}=\frac{-1}{C} \int V_{s d} d t
$$

$$
R_{L} i_{L q}+L_{L} \frac{d i_{L q}}{d t}+i_{s q}=\frac{-1}{C} \int V_{s q} d t
$$

The previous Eqs. (7-16) are used to develop a dynamic model of three phase SEIG using MatLab/Simulink.

\section{Teaching Learning Based Optimization (TLBO) algorithm}

The TLBO is a nature-inspired algorithms optimization method developed by Rao [2122].TLBO algorithm uses a population of solutions to have the global solution. The population is considered as a group of learners and consists of different variables which are similar to subjects of learners. The algorithm of TLBO consists of 'Teacher Phase' and 'Learner Phase'. The learners are learning from the teacher in the 'Teacher Phase', and learning from each other in the 'Learner Phase'. Similar to other evolutionary methods, the random initialization of the student population is the first step of the TLBO process. Then, the mean of each subject (variable) is calculated.

The Teacher-phase starts by selecting the best student of the class which is considered as a teacher $\left(\mathrm{X}_{\text {teacher }}\right)$ and the other students learn from him to improve their qualities by using the following expression shown in Eq. (17) [21].

$$
\mathrm{X}_{\text {new }, \mathrm{i}}=\mathrm{X}_{\mathrm{old}, \mathrm{i}}+\mathrm{r}_{\mathrm{i}}\left(\mathrm{X}_{\text {teacher }}-\mathrm{T}_{\mathrm{F}} \mathrm{M}_{\mathrm{i}}\right)
$$

Where; $X_{n e w, i}$ is the updated new solution, $X_{o l d, i}$ is the old solution, $r_{i}$ is a random number in the range $[0,1], \mathrm{M}_{\mathrm{i}}$ is the mean of each subject (variable) and $\mathrm{T}_{\mathrm{F}}$ is a teaching factor that determines the learning intensity and decides the value of mean to be changed. Its value can be either 1 or 2 , which is decided randomly with equal probability as:

$$
\mathrm{T}_{\mathrm{F}}=\operatorname{round}[1+\operatorname{rand}(0,1)\{2-1\}]
$$

As shown from above equation, in this phase, all students learn from both class (by using the mean values) and teacher (best solution) qualities The new solution is accepted if it is better than the previous one. After updating solutions, the second learning phase (Learner-phase) starts by selecting randomly any two solutions $X_{i}$ and $X_{j}$. The objective function of $X_{i}$ and $X_{j}\left(f\left(X_{i}\right)\right.$ andf $\left.\left(X_{j}\right)\right)$ are calculated and used to updated the solutions according to the following equation.

$$
\begin{cases}\mathrm{X}_{\text {new }, \mathrm{i}}=\mathrm{X}_{\text {old }, \mathrm{i}}+\mathrm{r}_{\mathrm{i}}\left(\mathrm{X}_{\mathrm{i}}-\mathrm{X}_{\mathrm{j}}\right) & \mathrm{f}\left(\mathrm{X}_{\mathrm{i}}\right)<f\left(\mathrm{X}_{\mathrm{j}}\right) \\ \mathrm{X}_{\text {new }, \mathrm{i}}=\mathrm{X}_{\text {old }, \mathrm{i}}+\mathrm{r}_{\mathrm{i}}\left(\mathrm{X}_{\mathrm{j}}-\mathrm{X}_{\mathrm{i}}\right) & \mathrm{f}\left(\mathrm{X}_{\mathrm{j}}\right)<f\left(\mathrm{X}_{\mathrm{i}}\right)\end{cases}
$$

The new value of the solution $\left(\mathrm{X}_{\text {new }}\right)$ is accepted if it gives a better function value and the process is terminated if the termination criteria are satisfied. 


\section{Simulation and results using TLBO algorithm}

The three phase induction motor used in this study has the following nameplate data and parameters: 7.5 $\mathrm{kW}, 4$ poles, $415 \mathrm{~V}, 50 \mathrm{~Hz}, 14.6 / 26.2 \mathrm{~A}, \mathrm{R}_{\mathrm{S}}=1 \Omega$, $\mathrm{R}_{\mathrm{R}}=0.77 \Omega, \mathrm{L}_{1}=0.004774 \mathrm{H}, \mathrm{L}_{2}=0.004774 \mathrm{H}$ and $\mathrm{J}=0.1384 \mathrm{~kg} \cdot \mathrm{m}^{2}$.

The magnetization curve of the machine is described as:

$L_{m}$
$=\left\{\begin{array}{cc}0.13771 & i_{m}<3.16 \\ \left(9 \times 10^{-5}\right) i_{m}^{2}-\left(0.0087 i_{m}\right)+0.1643 & 3.16<i_{m}<12.71 \\ \frac{0.068}{i_{m}} & i_{m}>12.71\end{array}\right.$

\subsection{Constant voltage operation at constant speed}

In this mode of operation, the excitation capacitor is controlled to operate SEIG at rated voltage when it driven from constant speed prime mover. The TLBO algorithm searches for the values of capacitor (C) and frequency ratio $(a)$ to minimize the Objective Function (OF). The OF is the error between the load voltage $(V)$, rated value $\left(V_{\text {rated }}\right)$ and error between generator speed $(n)$, prime mover speed ( $\left.n_{\text {prime mover }}\right)$ as shown in Eq. $(21)$. The TLBO adapted parameters are, class size $=50$ and iterations $=100$.

$$
\begin{aligned}
O F=\operatorname{Minimize} & \left\{\left|V-V_{\text {rated }}\right|\right. \\
& \left.+\left|n-n_{\text {prime mover }}\right|\right\}
\end{aligned}
$$

At a given load current, power factor and prime mover speed, the TLBO is run for 20 times and best solution is picked up. The trend of variation the objective function versus iteration is shown in Fig. 2 at no load and prime mover speed is adjusted at 1500 rpm. It can be notice that the TLBO converges steadily and in smoothly. Table 1 summarizes the performance measures out of 20 runs at no load and speed of $1500 \mathrm{rpm}$. One can notice obviously the deviations between results of each run are very small and the value of standard deviation is insignificant (see Table 1).

The variations of generator characteristics versus load current of unity power (UPF) at different constant speed are shown in Fig. 3. It's shown that the output voltage is maintained constant at rated value by controlling the capacitor as shown in Fig. 3(b). The generator frequency depends on load current and generator speed. It decreases with load increasing but for the same load current it can be increased by increasing speed as depicted in Fig. 3(c). The generator develops the same load current with lower stator current when the generator speed is increased as shown in Fig. 3(d). The stator current has full load value 14.6 A when the load current of 10.9 A and UPF.

The waveform of the output voltage when load varied from no load $\left(R_{L}=\infty\right)$ to resistive load $\left(R_{L}=24 \Omega\right)(10 \mathrm{~A}, \mathrm{UPF})$ at $\mathrm{t}=6 \mathrm{~s}$ and constant speed of $1500 \mathrm{rpm}$ is shown in Fig. 4. It's shown that the output voltage is maintained at rated value because the excitation capacitor is increased from $88.0196 \mu F$ at no load to $128.071 \mu F$ at load of 10 A as calculated using TLBO algorithm from Fig. 3(b).

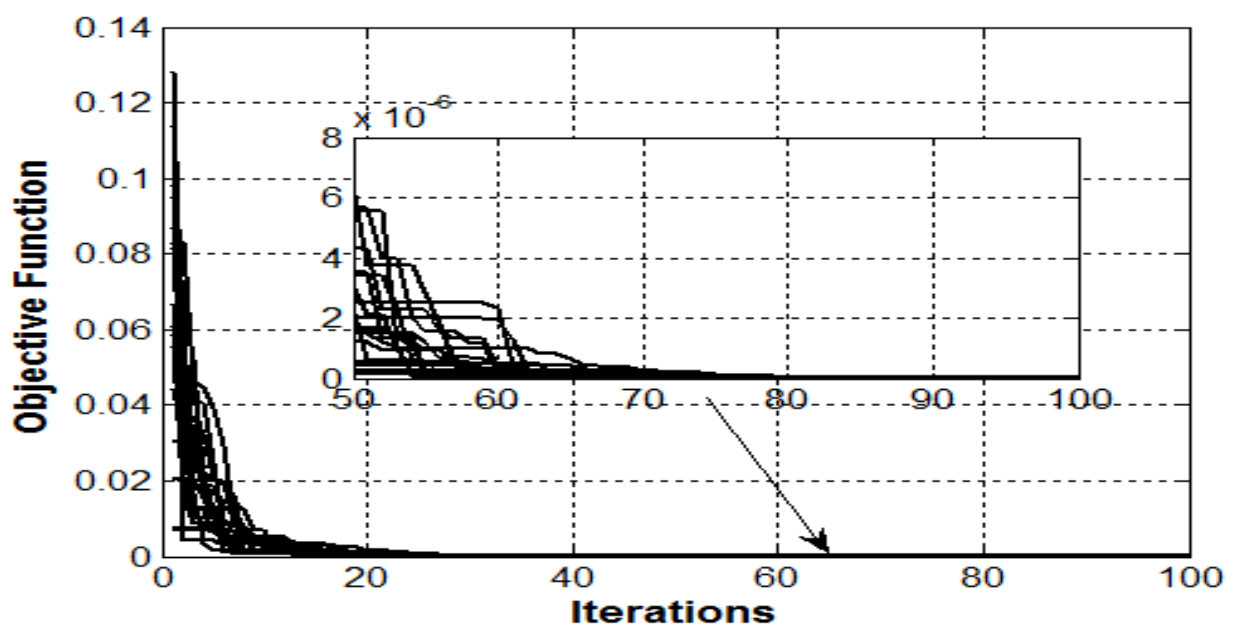

Fig. 2 Convergence of TLBO objective function 
Table 1 Statistical analysis of TLBO results at no load and $1500 \mathrm{rpm}$

\begin{tabular}{|c|c|c|c|}
\hline $\begin{array}{c}\text { Statistical } \\
\text { function }\end{array}$ & $a=f / f b$ & $C(\mu F)$ & $O F$ \\
\hline Minimum & 0.999360991067669 & 88.0196113861336 & $9.80345286431353 \times 10^{-12}$ \\
\hline Maximum & 0.999360991445124 & 88.0196114687359 & $4.65723905070566 \times 10^{-10}$ \\
\hline Mean & 0.999360991221912 & 88.0196114300202 & $1.63121186602666 \times 10^{-10}$ \\
\hline $\begin{array}{c}\text { Standard } \\
\text { Deviation }\end{array}$ & $1.1096244330 \times 10^{-10}$ & $2.67086882 \times 10^{-8}$ & $1.36892107248994 \times 10^{-10}$ \\
\hline
\end{tabular}

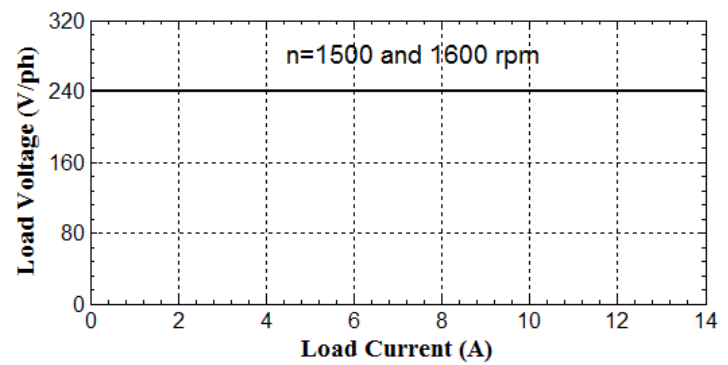

(a)

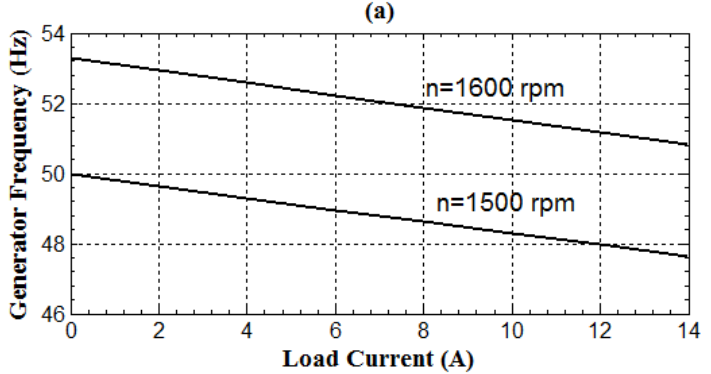

(c)

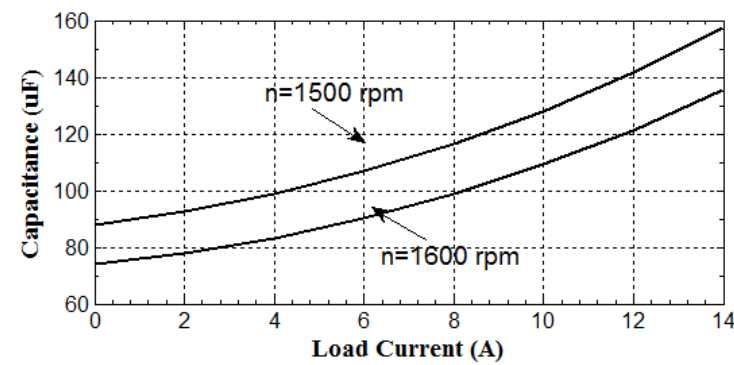

(b)

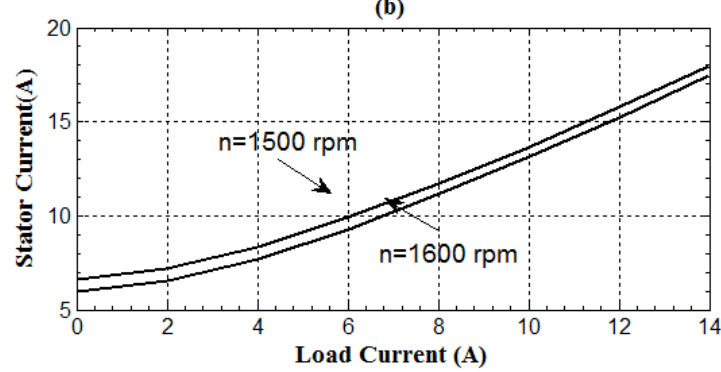

(d)

Fig. 3 Variation of load voltage, frequency, capacitance and stator current against load current of UPF and different constant speed

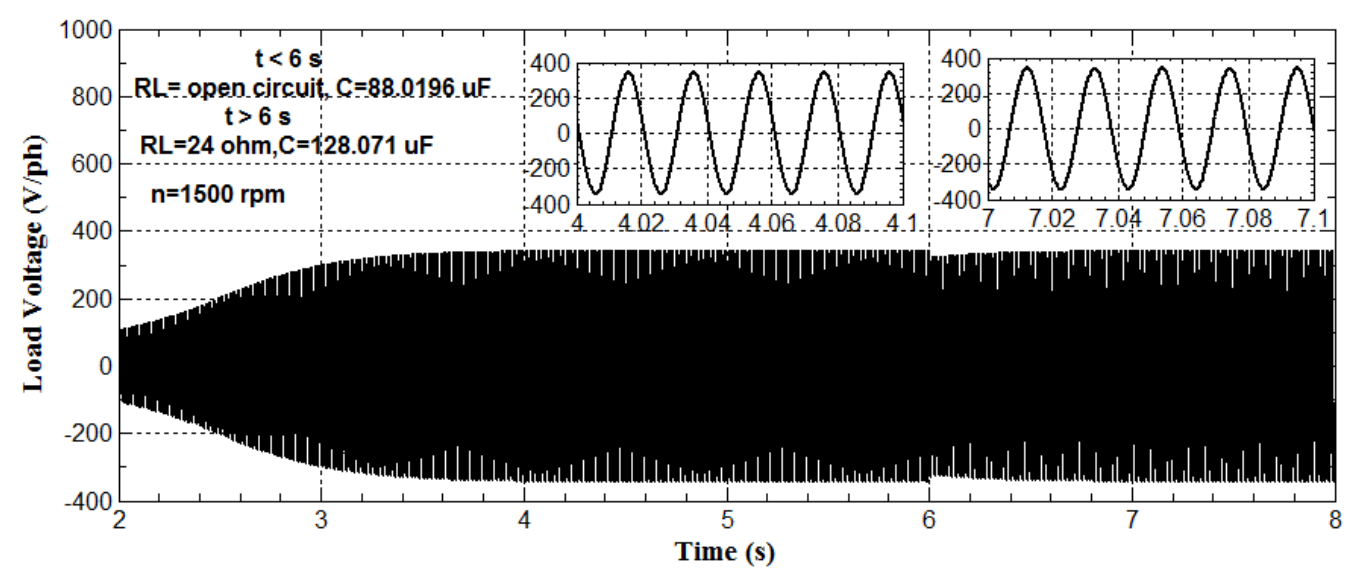

Fig. 4 Waveform of the load volatge against time at different loads and $n=1500 \mathrm{rpm}$

\subsection{Constant voltage constant frequency operation}

In this mode of operation, both excitation capacitor and prime mover speed are controlled to operate SEIG at rated voltage and frequency at all loading conditions. The TLBO algorithm searches for the value of capacitor $(\mathrm{C})$ with keeping frequency ratio (a) at unity. The OF is the error between the load voltage $(V)$, rated value $\left(V_{\text {rated }}\right)$ as shown in Eq. (22).

$$
O F=\operatorname{Minimize}\left\{\left|V-V_{\text {rated }}\right|\right\}
$$

The TLBO results are used to calculate the steady state performance of SEIG when its load has been varied from no load to $14 \mathrm{~A}$ at UPF as shown in Fig. 5. It's shown that, the load voltage and frequency are maintained at rated values $(240 \mathrm{~V}$ and $50 \mathrm{~Hz})$ over all range of loads by controlling both excitation capacitor and prime mover speed as described in Figs. 5(b) and (c) respectively. The stator current has 
full load value 14.6 A when the load current of 11.2 A and UPF as given in Fig. 5(d). It's shown from Fig. 6, the waveform of the load voltage has constant amplitude and frequency at different loads by

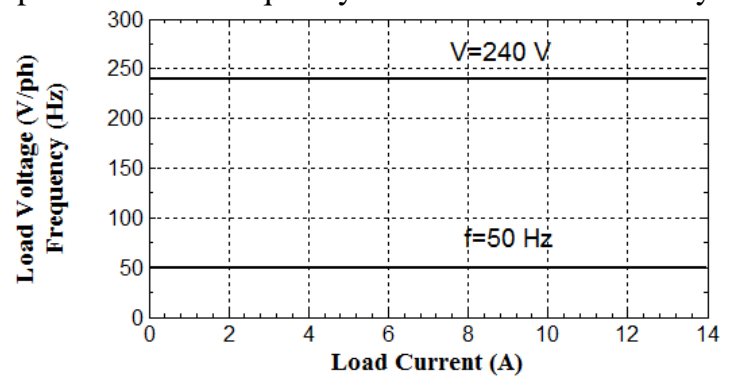

(a)

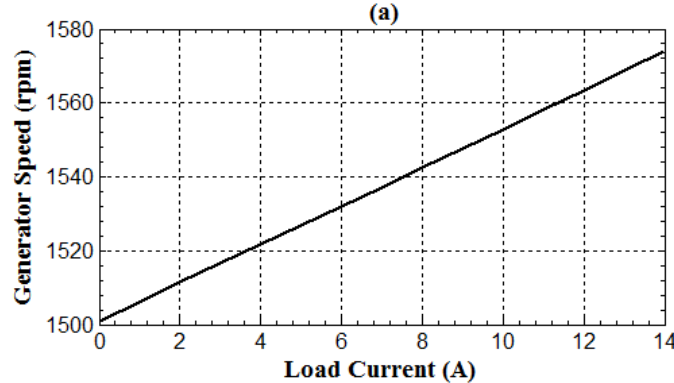

(c) changing capacitor and speed from $87.86436 \mu F$, $1500.957 \mathrm{rpm}$ at no load to $117.23017 \mu \mathrm{F}$, $1552.844 \mathrm{rpm}$ at load current of $10 \mathrm{~A}\left(R_{L}=24 \Omega\right)$.

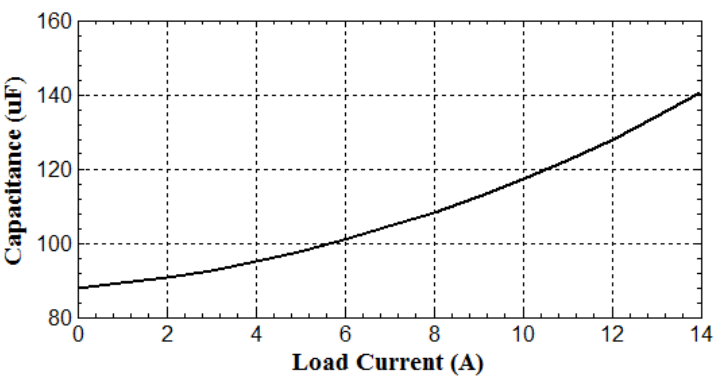

(b)

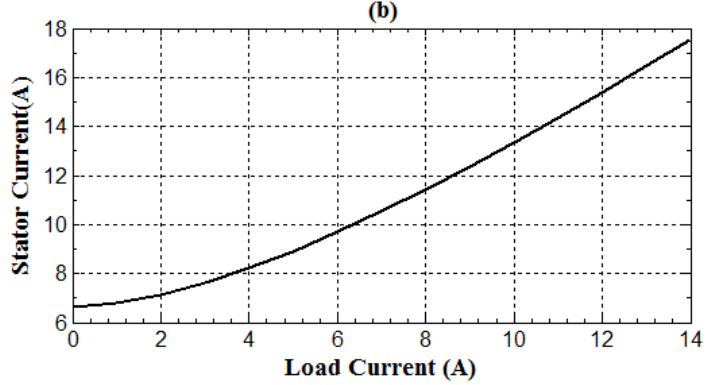

(d)

Fig. 5 Variation of load voltage, frequency, capacitance, speed and stator current against load current of UPF with controlled capacitor and prime mover speed

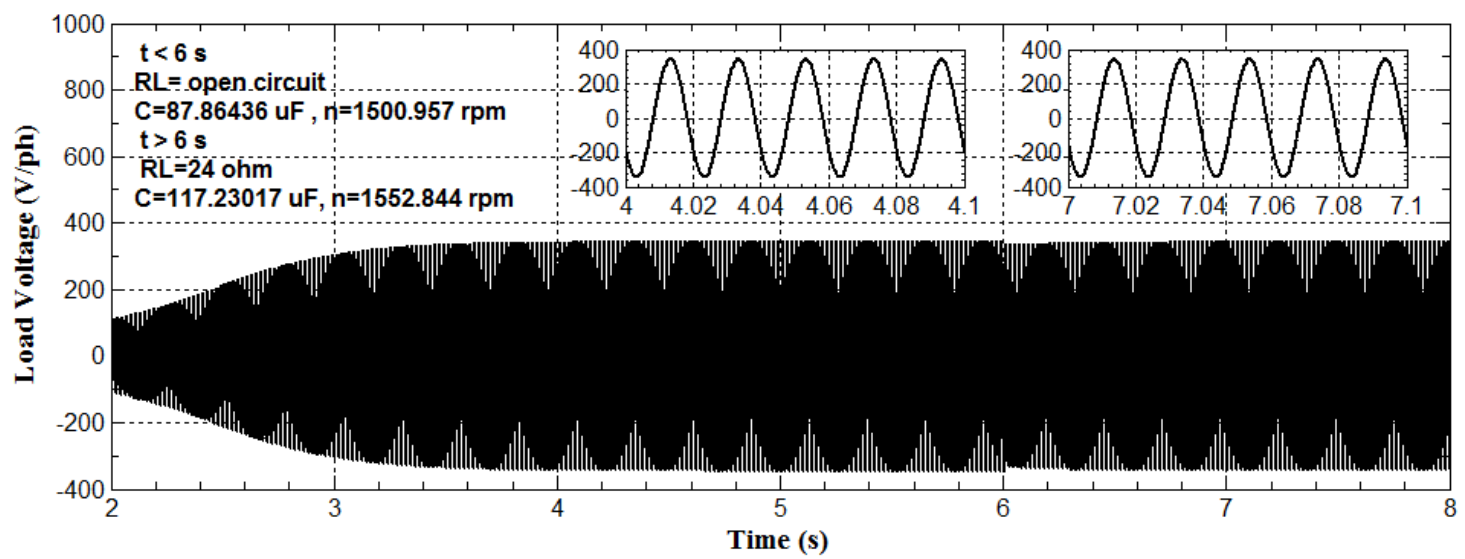

Fig. 6 Waveform of the load volatge against time at different loads with controlled capacitor and prime mover speed

\section{Dynamic performance with SVC controller}

In this section, the excitation capacitor is controlled using SVC to regulate the generator voltage at its rated value. The generator frequency is fixed at rated vale by controlling the prime mover governor. The SVC consists of fixed three phase capacitors parallel with thyristor controlled reactor (TCR) as shown in Fig.7. The effective capacitance $\left(\mathrm{C}_{\text {eff }}\right)$ of the SVC is controlled by changing the firing angle $(\alpha)$ from $90^{\circ}$ (fully conducting) to $180^{\circ}$ (non-conducting) as described in Eq. (23) [28].

$$
\mathrm{C}_{\mathrm{eff}}=\mathrm{C}_{\mathrm{fixed}}-\frac{1}{\omega^{2} \mathrm{~L}}\left(2-\frac{2 \alpha}{\pi}+\frac{\sin 2 \alpha}{\pi}\right)
$$

Where; $\mathrm{L}$ is the TCR inductance and $\mathrm{C}_{\mathrm{fixed}}$ is the capacitance of fixed capacitor.

The inductance of TCR is calculated by using Eq. (24) to have the desired range of controlled capacitor from minimum value at no load $\left(\mathrm{C}_{\min }\right)$ to maximum value at full load $\left(\mathrm{C}_{\max }\right)$.

$$
\mathrm{L}=\frac{1}{\omega^{2}\left(\mathrm{C}_{\max }-\mathrm{C}_{\min }\right)}
$$

The following results are simulated with $C_{\max }=$ $180 \mu F, C_{\text {min }}=75 \mu F(\mathrm{~L}-\mathrm{N})$ and $L=96.496 \mathrm{mH}$ $(\mathrm{L}-\mathrm{N})$. The constants of proportional-integral (PI) SVC are $K_{p}=0$ and $K_{i}=800$. The simulation sampling time is $5 \times 10^{-6} \mathrm{~s}$. 
The effective capacitance of SVC varies between minimum and maximum values by firing angle variation as shown in Fig. 8.

The complete control system of $7.5 \mathrm{~kW}, 415 \mathrm{~V}$ three phase induction machine is tested with two different scenarios. The first scenario is the dynamic response under constant speed and SVC control with different loading conditions. The other one is the response with controlled speeds and SVC.

The Simulink connection diagram of the SEIG dynamic model, SVC and controller is revealed in Fig. 9.

\subsection{Response with Constant Speed and SVC}

In this scenario, the prime mover speed is constant at $1500 \mathrm{rpm}$ and the load is varied as described in Fig. $10(\mathrm{a})$. The load current is changed from no load $\left(R_{L}=\infty\right)$ to $4 \mathrm{~A}$ with $\operatorname{UPF}\left(\left(R_{L}=60 \Omega\right)\right.$ at $\mathrm{t}=6 \mathrm{~s}$ and to $8 \mathrm{~A}$ with 0.8 lagging power factor at $12 \mathrm{~s}$ $\left(R_{L}=37.5 \Omega\right.$ parallel with $\left.L_{L}=0.16 \mathrm{H}\right) . \quad$ The $\mathrm{SVC}$ varies the firing angle to increase the excitation current (increase effective capacitance) with increasing in load current as shown in Fig. 10(b). This variation in SVC current regulates the generated voltage at rated value $(240 \mathrm{~V})$ as shown in Fig. 10(c). The generator frequency decreases with load current increase as described in Fig. 10(d) because the prime mover speed is constant at 1500 rpm. It's shown that, the waveform of the load voltage has constant amplitude and variable frequency with increasing in load current as shown in Fig. 11.

\subsection{Response with controlled Speed and SVC}

In this scenario, excitation capacitor and prime mover governor are controlled to have rated voltage and frequency with load current variation as shown in Fig. 12(a). The prime mover speed and SVC current are controlled as shown in Fig. 12(b) to have rated voltage and frequency as shown in Figs. 12(cd). The waveform of the output voltage is sinusoidal with constant amplitude and frequency at different loads as shown in Fig. 13.
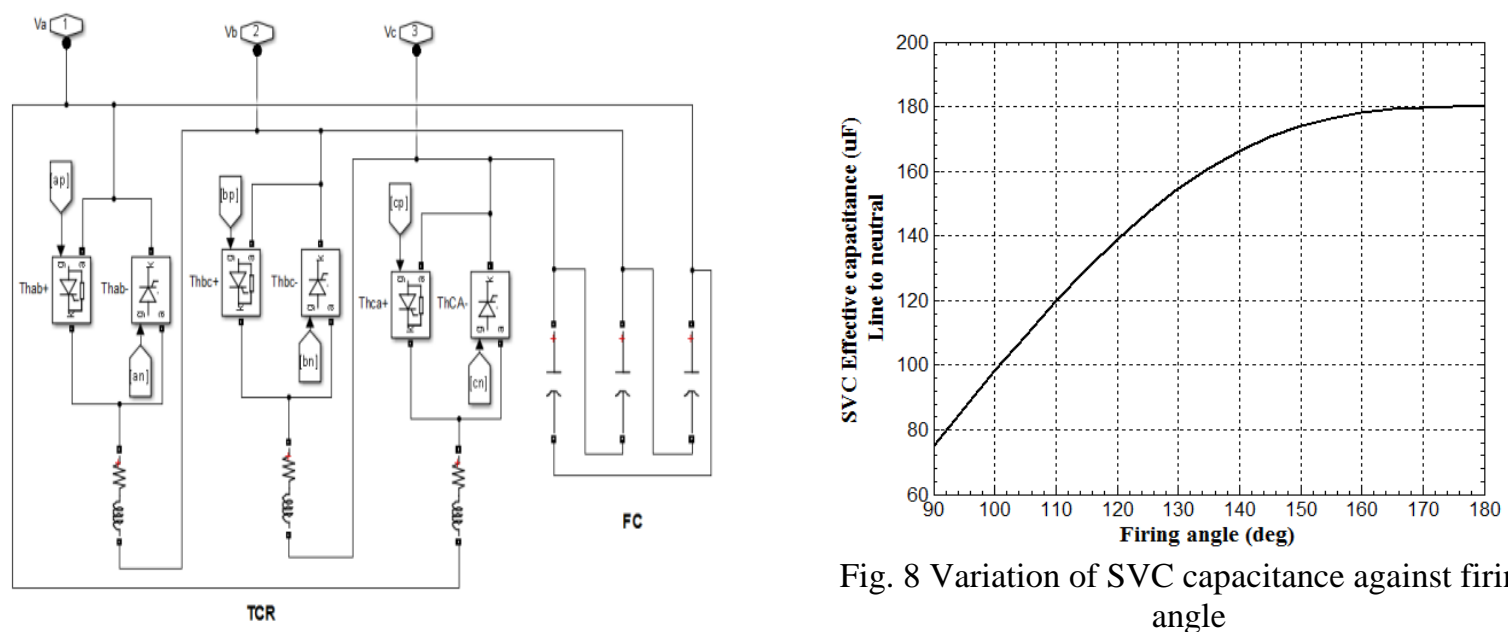

Fig. 8 Variation of SVC capacitance against firing

Fig. 7 SVC configuration

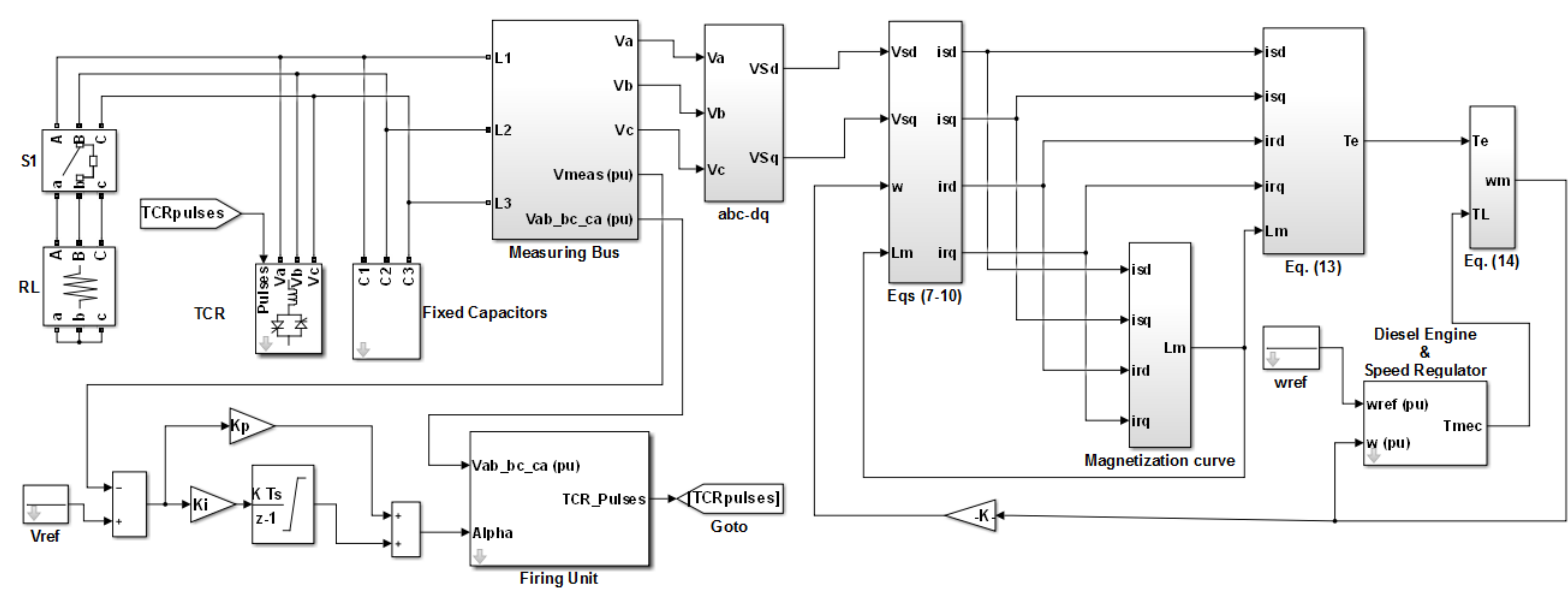

Fig. 9 Simulink diagram of SEIG and control system 

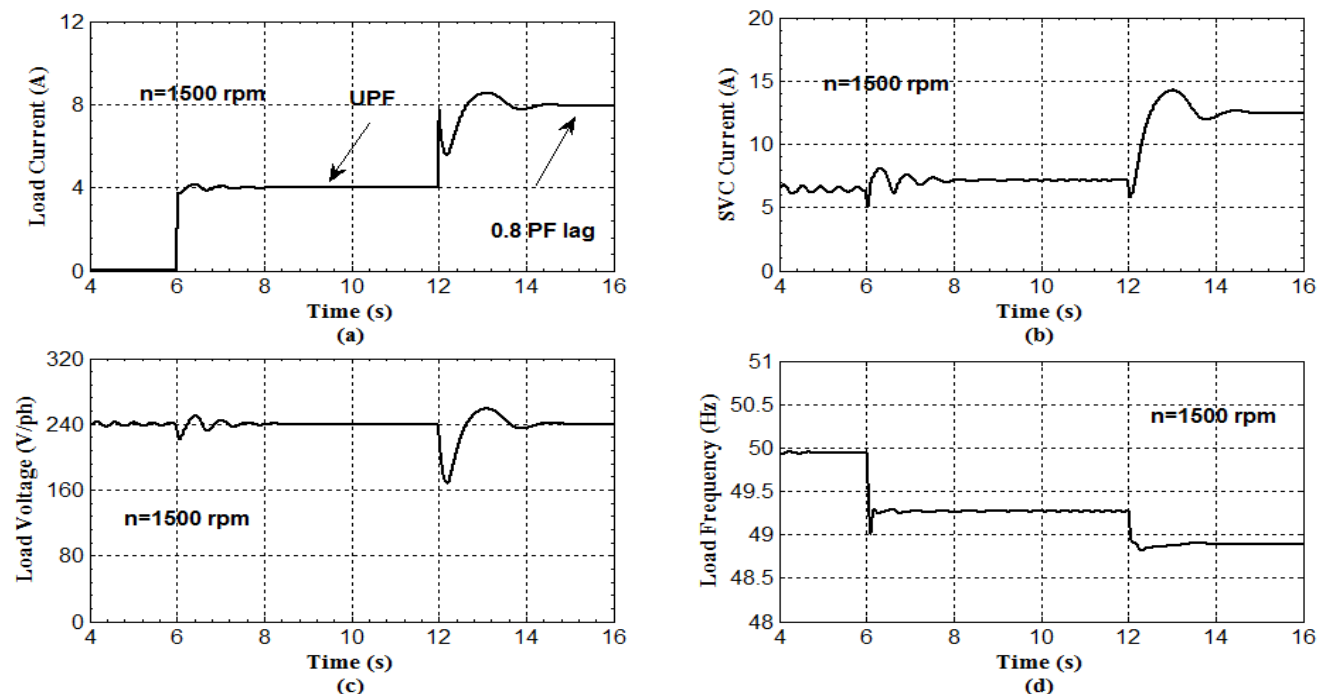

Fig. 10 Variation of load current, SVC current, load voltage and frequency versus time and $n=1500 \mathrm{rpm}$

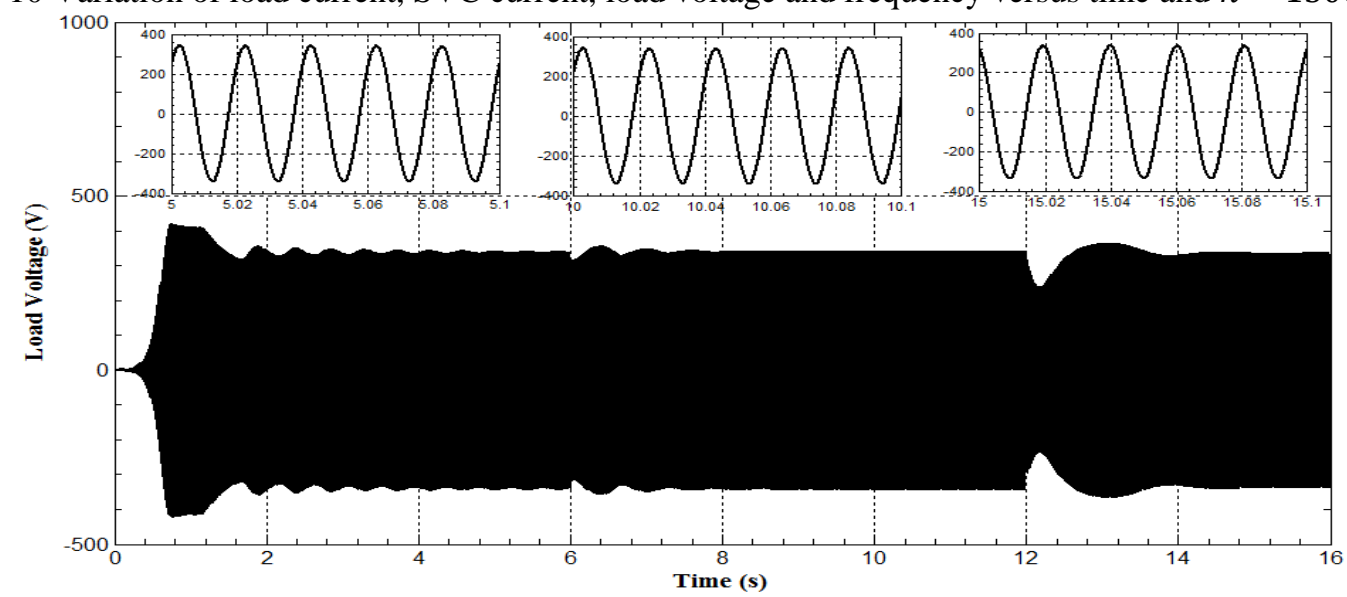

Fig. 11 Variation of phase voltage waveform versus time with load change and $n=1500 \mathrm{rpm}$

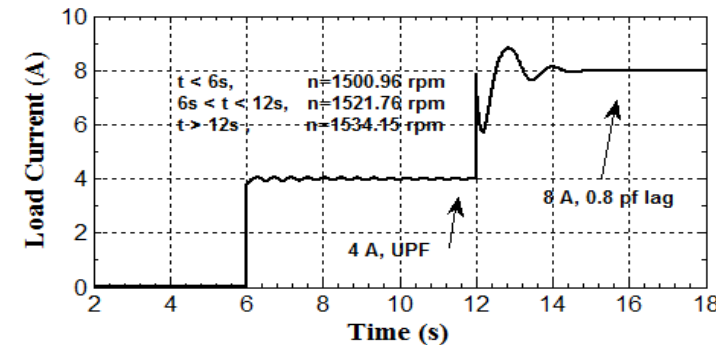

(a)

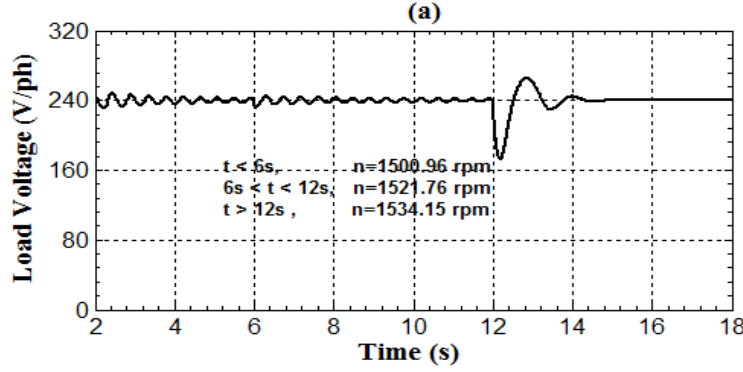

(c)

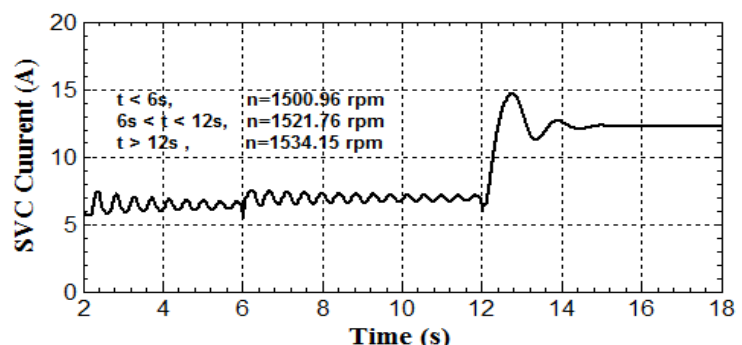

(b)

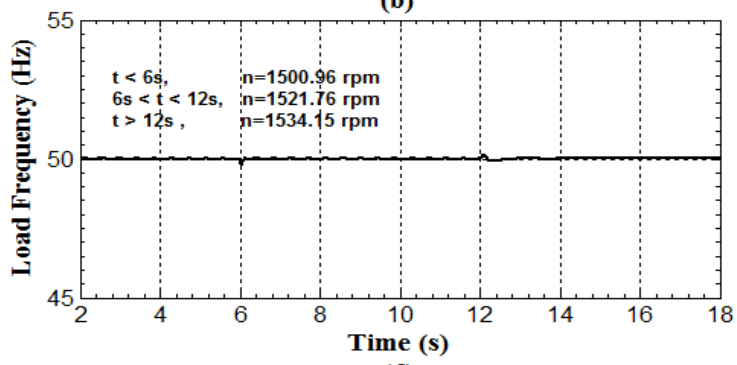

(d)

Fig. 12 Variation of load current, SVC current, load voltage and frequency versus time at constant load current and different speeds 


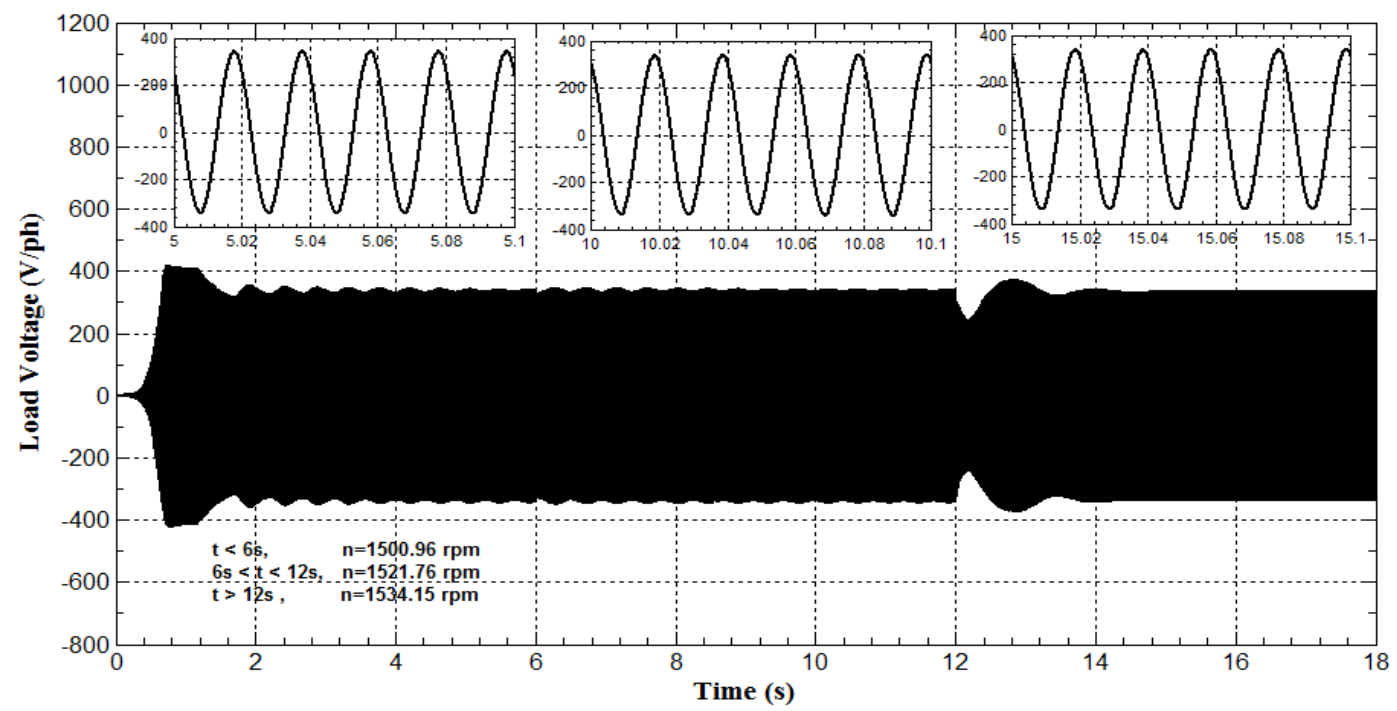

Fig. 13 waveform of load voltage against time with constant load and different speeds

\section{Experimental work}

An experimental model is built up to validate the steady state and dynamic models of SEIG. The experimental work is carried out using $2 \mathrm{hp}, 4$ poles, $220 / 380 \mathrm{~V}$ three phase induction machine having the following parameters; $\mathrm{R}_{\mathrm{S}}=5.03 \Omega, \mathrm{R}_{\mathrm{R}}=5.94 \Omega$, $\mathrm{L}_{1}=0.0176 \mathrm{H}$ and $\mathrm{L}_{2}=0.0176 \mathrm{H}$.

The magnetizing curve of the experimental motor is described as:

$$
\begin{aligned}
& \mathrm{L}_{\mathrm{m}} \\
& =\left\{\begin{array}{lc}
0.3582 & \mathrm{i}_{\mathrm{m}}<1 \\
(0.0052) \mathrm{i}_{\mathrm{m}}{ }^{3}-(0.029) \mathrm{i}_{\mathrm{m}}{ }^{2}-(0.028) \mathrm{i}_{\mathrm{m}}+0.41 & 1<\mathrm{i}_{\mathrm{m}}<4 \\
\frac{0.1668}{\mathrm{i}_{\mathrm{m}}} & \mathrm{i}_{\mathrm{m}}>4
\end{array}\right.
\end{aligned}
$$

A synchronous motor is used as a constant speed prime mover and all results are recorded using data acquisition system of Feedback 68-600 multichannel power sensor which is a combination of hardware and software to capture and display signals on the integrated DSP instrumentation in Espial as shown in Fig. 14.

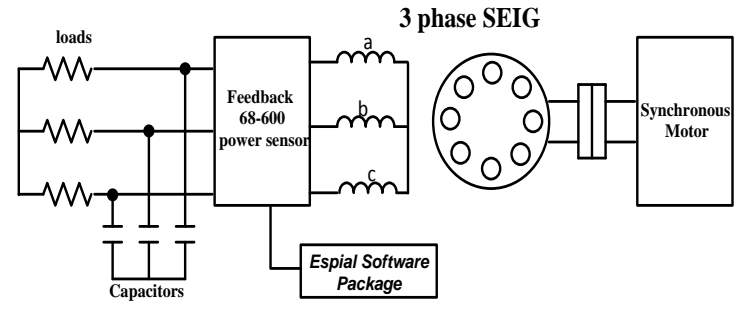

Fig. 14 Experimental Connection Diagram

The experimental and theoretical waveforms of the generator line voltage at no load at excitation capacitor of $40 \mu F$ and $50 \mu F$ with speed of 1500 rpm are shown in Fig. 15(a-b). It's shown that the both results are very close together and this agreement validates the simulink model of SEIG.

The variation of load voltage and stator current against load current at constant speed of $1500 \mathrm{rpm}$ and different capacitors of $40 \mu F$ and $50 \mu F$ is shown in Fig. 16(a)-(b) respectively. The agreement between theoretical and experimental validates the steady state model of SEIG and TLBO results. 

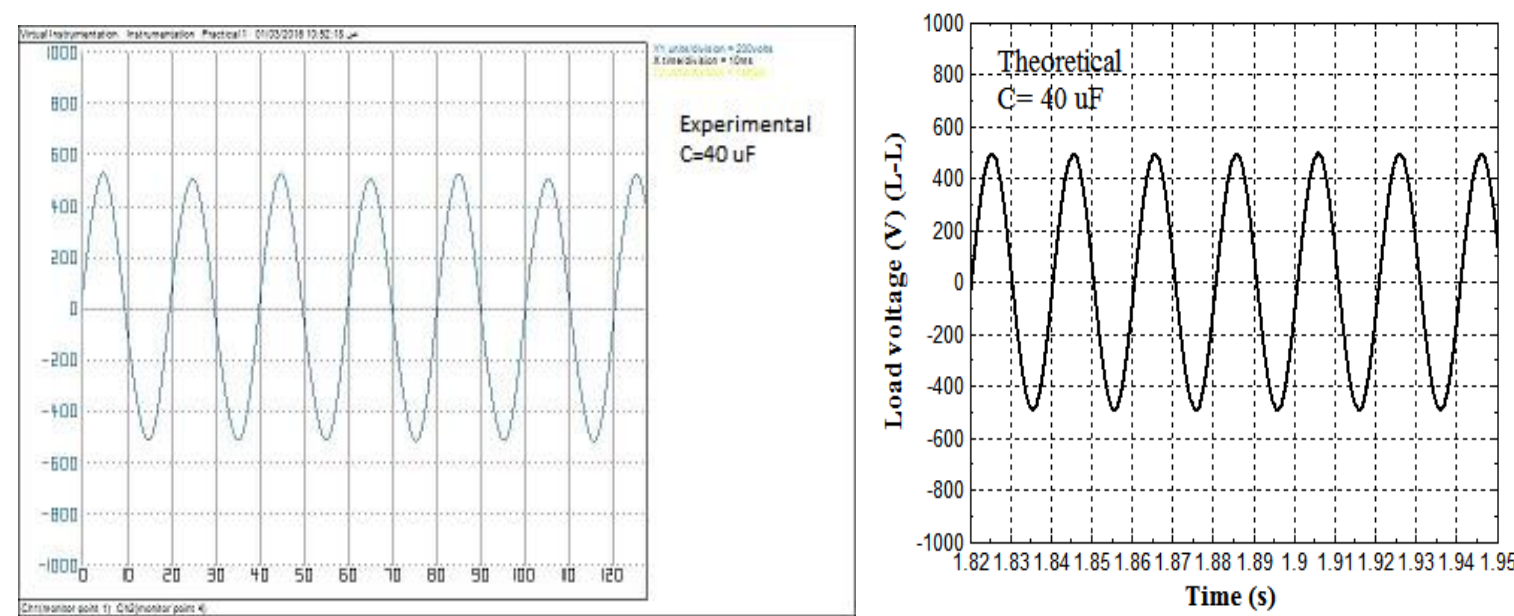

(a)
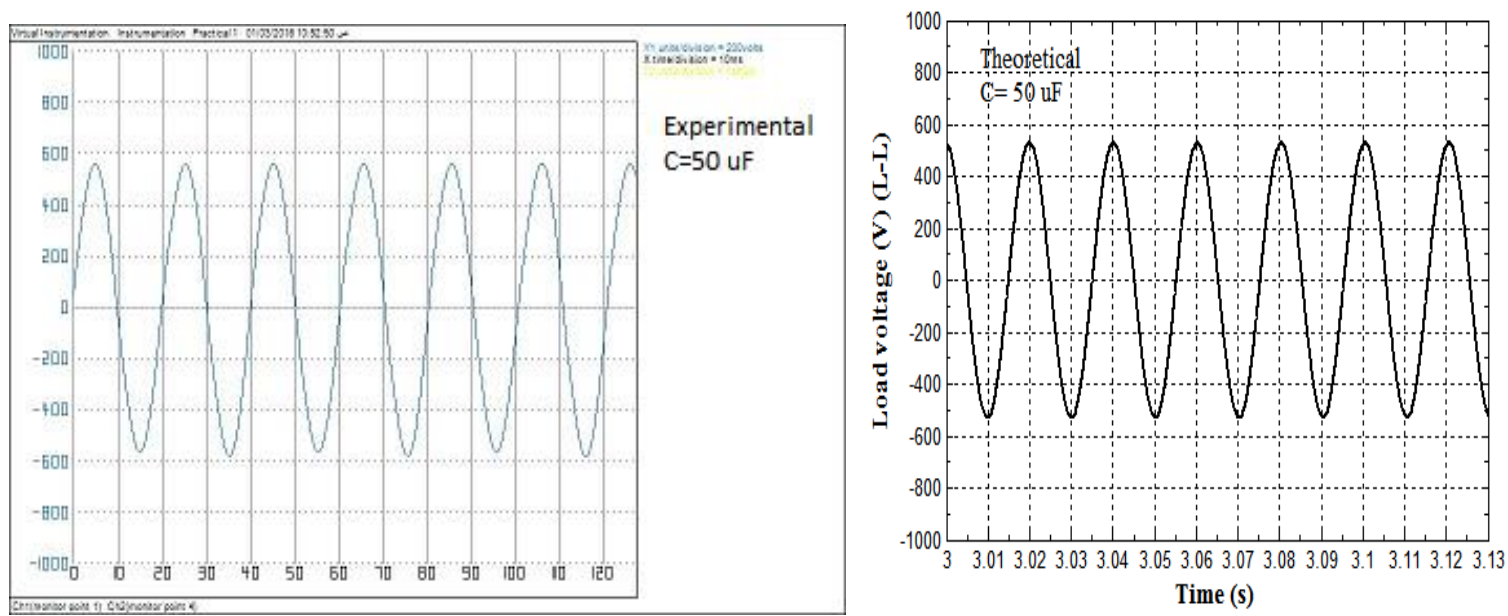

(b)

Fig. 15 Experimental and theoretical waveform of the line voltage at no load and $1500 \mathrm{rpm}$

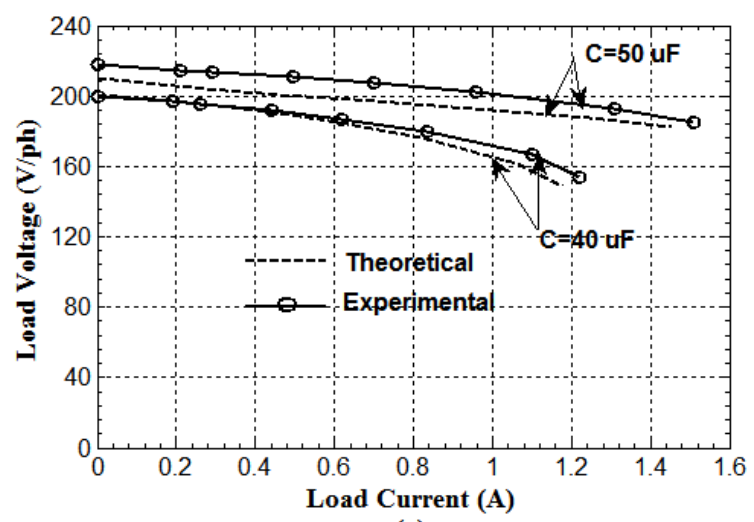

(a)

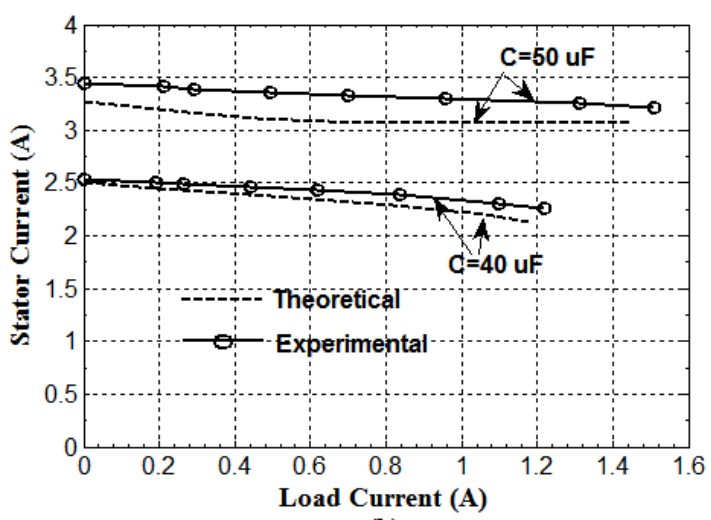

(b)

Fig. 16 Experimental and theoretical load voltage and stator current against load current

\section{Conclusions}

In this paper, the methodology based on TLBO algorithm has been proposed to study the performance of self-excited induction generator (SEIG). The TLBO algorithm is used to produce optimal excitation capacitors required to have rated voltage at different load currents, power factors and speeds. The operation with constant voltage and constant prime mover speed has been studied. The operation with constant voltage and frequency has been achieved by controlling both capacitor and prime mover speed. The SVC method is used to have continuous change in capacitor to maintain 
rated voltage. The proposed TLBO algorithm is used to generate the value of SVC fixed capacitor. The dynamic performance of the $7.5 \mathrm{~kW}$ induction generator with SVC and PI controller under different step load changes and speeds are demonstrated using Matlab/Simulink. The good agreement between experimental and theoretical results of $2 \mathrm{hp} \mathrm{SEIG}$ validate the feasibility of the proposed TLBO algorithm, accuracy of steady state and dynamic model of SEIG.

\section{References}

[1] G. K. Singh, Self-excited induction generator research - a survey, Electric Power Systems Research, vol. 69, pp. 107-114, 2004.

[2] A. K. Aljabri and A. I. Alolah, Capacitance Requirement for Self Excited Induction Generator, IEE Proceedings B, vol. 137, pp.154-159, 1990.

[3] R. C. Bansal, Three-phase self-excited induction generators: an overview, IEEE Transactions on Energy Conversion, vol. 20, no. 2, June 2005.

[4] L. Shridhar, B. Singh, C. S. Jha, B.P Singh and S.S. Murthy, Selection of capacitors for the self -regulated short shunt self-excited induction generator, IEEE Transactions on Energy conversion, Vol. 18, no. 1, pp. 10 - 17, 1995.

[5] B. Sawetsakulanond and V. Kinnares, A simple approach to capacitance determination of self exited induction generators for terminal voltage regulation, $7^{\text {th }}$ International Conference on Power Electronics and Drive Systems (PEDS '07), Thailand, 27-30 Nov. 2007, pp. 1319-1324.

[6] Mustafa A. Al Saffar, Eui Cheol Nho and Thomas A. Lipo, Control shunt capacitor selfexcited induction generator, IEEE Transactions on Energy Conversion, vol. 17, pp. 1486-1490, 1998.

[7] Vineet P. Chandran and Shelly Vadhera, Capacitance requirements of self excited induction generator for different operating conditions, IEEE International Conference on Energy, Automation, and Signal (ICEAS) Bhubaneswar, India, 28-30 Dec. 2011, pp. 1-6.

[8] T. Ahmed, O. Noro, E. Hiraki and M. Nakaok, Terminal voltage regulation characteristics by static var compensator for a three-phase selfexcited induction generator, IEEE transactions on industry applications, vol. 40, no. 4, pp. 978 - 988, 2004.

[9] T. Ahmed, K. Ogura, K. Soshin, E. Hiraki and H. Nakaoka, Small-scale wind turbine coupled single-phase self-excited induction generator with svc for isolated renewable energy utilization, IEEE Fifth International Conference on Power Electronics and Drive Systems Singapore, 17-20 Nov. 2003, pp. 781-786.
[10] B. Sawetsakulanond and V. Kinnares, Investigation on the behavior and harmonic voltage distortion of terminal voltage regulation by static VAR compensators for a three phase self-exited induction generator, IEEE International Conference on Sustainable Energy Technologies (ICSET) - Singapore, 27-28 Nov. 2008, pp. 483-488.

[11] B.Venkatesa Perumal and J.K.Chatterjee, Analysis of a self excited induction generator with statcom/battery energy storage system, IEEE Power India Conference, New Delhi, India, 10-12 April 2006, pp.717-722.

[12] G. V. Jayaramaiah and B. G. Fernandes, Novel voltage controller for sand alone induction generator using PWM-VSI, IEEE Industry Applications Conference $41^{\text {st }}$ IAS Annual Meeting - 2006, pp. 204-208.

[13] S. S. Murthy and Kr. Ahuja, A novel solid state voltage controller of three phase self excited induction generator for decentralized power generation, IEEE International Conference on Power, Control and Embedded Systems (ICPCES) - Allahabad, India, 29 Nov.-1 Dec. 2010, pp. 1-6.

[14] Li Wang and Dong-Jing Lee, Coordination control of an ac-to-dc converter and a switched excitation capacitor bank for an autonomous self-excited induction generator in renewableenergy systems, IEEE Transactions on Industry Applications, vol. 50, no. 4, pp. 2828-2836, 2014.

[15] Jordan G. Trapp, Jocemar B. Parizzi, Felix A. Farret, Álvaro B. Serdotte and Adriano J. Longo, Stand alone self-excited induction generator with reduced excitation capacitors at fixed speed, IEEE Brazilian Power Electronics Conference (COBEP 2011) - Natal, Brazil, 1115 Sept. 2011, pp. 955-962.

[16] Bhim Singh, S.S. Murthy, Madhusudan, Manish Goel, and A. K.Tandon, A steady state analysis on voltage and frequency control of self-excited induction generator in micro-hydro system, IEEE International Conference on Power Electronic, Drives and Energy Systems, 12-15 Dec. 2006, pp.1-6.

[17] Mahmoud M.Elkholy and Mohammed A. Elhameed, Neuro-Genetic Adaptive Optimal Controller for DC Motor, International Journal of Power Electronics and Drive System (IJPEDS), vol.4, no.3, pp. 393-399, 2014.

[18] Mahmoud M.Elkholy and Mohammed A. Elhameed, Braking of three phase induction motors by controlling applied voltage and frequency based on particles warm optimization technique, International Review of Automatic Control (I.RE.A.CO.), vol. 8, no. 2, pp.106-112, 2015. 
[19] Dong Hwa Kim, GA-PSO based vector control of indirect three phase induction motor, Applied Soft Computing, vol. 7, pp.601-611, 2007.

[20] Sakuntala Mahapatra, Raju Daniel, Deep Narayan Dey and Santanu Kumar Nayak, Induction motor control using PSO-ANFIS, Procedia Computer Science, vol. 48, pp.754769, 2015.

[21] R.V. Rao, V.J. Savsani and D.P. Vakharia, Teaching-learning-based optimization: A novel method for constrained mechanical design optimization problems. Computer-Aided Design, vol. 43, pp. 303-315, 2011.

[22] R.V. Rao, V.J. Savsani and D.P. Vakharia, Teaching-Learning-Based Optimization: An optimization methodfor continuous non-linear large scale problems, Information Sciences, vol 183, pp. 1-15, 2012.

[23] R. VenkataRao and V.D.Kalyankar, Parameter optimization of modern machining processes using teaching-learning-based optimization algorithm, Engineering Applications of Artificial Intelligence, vol. 26, pp. 524-531, 2013.

[24] Pawar P. and Rao R., Parameter optimization of machining processes using teaching-learningbased optimization algorithm, International Journal of Advanced Manufacturing Technology; vol. 67, no. 5, pp. 995-1006, 2013.
[25] Mahmoud M. Neam, Fayez F. M. El-Sousy, Mohamed A. Ghazy and Maged A. Abo-Adma, The dynamic performance of an isolated selfexcited induction generator driven by a variable-speed wind turbine, IEEE 2007 International Conference on Clean Electrical Power - Capri, Italy , 21-23 May 2007, pp.536543.

[26] Garlapati Satish Kumar and Avinash Kishore, Dynamic analysis and control of output voltage of a wind turbine driven isolated induction generator, IEEE International Conference on Industrial Technology - Mumbai, India, 12-17 Dec. 2006, pp. 494-499.

[27] Avinash Kishore and G.Satish Kumar, A generalized state-space modeling of three phase self-excited induction generator for dynamic characteristics and analysis, IEEE $1^{\text {st }}$ Conference on Industrial Electronics and Applications -Singapore, 24 May 2006, pp.1-6.

[28] R. Mohan Mathur and Rajiv K. Varma, Thyristor-based facts controllers for electrical transmission systems, A John Wiley \&Sons, Inc. Publication, 2002.Author format, ISBN 0471-20643-1, chapter 3, pp.47-50. 